\title{
Barley Seedling Extracts Inhibit RANKL-Induced Differentiation, Fusion, and Maturation of Osteoclasts in the Early-to-Late Stages of Osteoclastogenesis
}

\author{
Sik-Won Choi, ${ }^{1}$ Shin-Hye Kim, ${ }^{1,2}$ Kwang-Sik Lee, ${ }^{1,3}$ Hyeon Jung Kang, ${ }^{1}$ Mi Ja Lee, \\ Kie-In Park, ${ }^{2}$ Jin Hwan Lee, ${ }^{4}$ Ki Do Park, ${ }^{1}$ and Woo Duck Seo ${ }^{1}$ \\ ${ }^{1}$ Division of Crop Foundation, National Institute of Crop Science (NICS), Rural Development Administration (RDA), \\ Jeonbuk 565-851, Republic of Korea \\ ${ }^{2}$ Department of Biological Sciences, College of Natural Science, Chonbuk National University, Jeonbuk 561-756, Republic of Korea \\ ${ }^{3}$ College of Crop Science and Biotechnology, Dankook University, Cheonan 330-714, Republic of Korea \\ ${ }^{4}$ Division of Research Development and Education, National Institute of Chemical Safety, Ministry of Environment, \\ Daejeon 305-343, Republic of Korea \\ Correspondence should be addressed to Woo Duck Seo; swd2002@korea.kr
}

Received 7 March 2017; Revised 3 April 2017; Accepted 18 April 2017; Published 8 May 2017

Academic Editor: Vishal Chandra

Copyright (c) 2017 Sik-Won Choi et al. This is an open access article distributed under the Creative Commons Attribution License, which permits unrestricted use, distribution, and reproduction in any medium, provided the original work is properly cited.

\begin{abstract}
The number of patients with osteoporosis is increasing worldwide, and a decrease in bone mass is a main risk factor for fracture. The prevention of bone loss is critical for improving the quality of life for patients. However, the long-term use of antiosteoporotic agents is limited due to their side effects. Barley has been traditionally ingested for thousands of years as a safe, natural food with pharmaceutical properties, and its seedling can enhance the biological activity of the medicinal components found in food. This study aimed to clarify the antiresorptive activity of barley seedling and its mode of action. Barley seedling extracts (BSE) dosedependently inhibited RANKL-induced osteoclast differentiation with alteration of I $\kappa$ B degradation, c-Fos, and NFATcl molecules in the early-to-middle stages of osteoclastogenesis. In the late phase of osteoclastogenesis, BSE also prevented DC-STAMP and cathepsin K, which are required for cell fusion and bone degradation, such as osteoclast function. In conclusion, barley seedling from natural foods may provide long-term safety and be useful for the prevention or treatment of osteoclast-mediated bone metabolic diseases, including osteoporosis.
\end{abstract}

\section{Introduction}

Bones are dynamic structures that are continually being formed and resorbed through the constant processes of remodeling and reorganisation. Bone homeostasis is sustained by a tight balance between osteoclast-mediated bone destruction and osteoblast-related bone formation. However, an imbalance of bone homeostasis by the induction of osteoclastic bone destruction or by the reduction of osteoblastic bone formation can lead to a variety of bone metabolic disorders, including osteoporosis, rheumatoid arthritis, and Paget's disease [1-3]. Most bone metabolic disorders induce the activation of osteoclasts; consequently, bone resorption can exceed bone formation and lead to pathological bone-resorbing activity resulting in osteopenic disorders with increased risk of fracture $[4,5]$. The economic burdens for hospitalisation, skeletal deformity, and pain due to fractures have become a serious public health issue worldwide [6]. Therefore, protection against bone loss and the risk of bone fracture is an essential means of improving the quality of patients' lives with bone defects.

The differentiation of osteoclasts is a complex multistep process that involves cell differentiation, migration, fusion, and resorption. In bone marrow, osteoclasts are multinucleated giant cells that resorb mineralised tissues; they are differentiated from hematopoietic stem cells by key regulators, such as receptor activator of NF- $\kappa \mathrm{B}$ ligand (RANKL) and macrophage colony-stimulating factor (M-CSF) [7]. M-CSF 
and RANKL trigger the differentiation of osteoclast precursors into mononuclear osteoclasts (preosteoclasts) and increase them to migrate until they attach to the bone matrix. Mononuclear osteoclasts then fuse to form giant multinucleated osteoclasts that, subsequently, relate to bone resorption. In the initial stage, the binding of RANKL to its receptor RANK triggers osteoclast differentiation by the activation of mitogen-activated protein (MAP) kinases and transcription factor, NF- $\kappa \mathrm{B}$ [8]. These essential signaling molecules contribute to the activation of c-Fos and nuclear factor of activated T cells, cytoplasmic 1 (NFATc1), which are known to be master regulators for osteoclast differentiation $[7,9,10]$. c-Fos is induced in the early-to-middle stages of osteoclastogenesis and NFATcl is increased in the middle-tolate phases. These two transcription factors play a critical role in the expression of specific genes, such as tartrate-resistant acid phosphatase (TRAP), osteoclast-associated receptor (OSCAR), dendritic cell-specific transmembrane protein (DC-STAMP), and cathepsin $\mathrm{K}$, which are required for osteoclast differentiation, cell fusion, and maturation. Thus, the regulation of osteoclast formation-mediated molecules is essentially responsible for the degradation of the mineralised matrix during physiological and pathological bone turnover [11].

For thousands of years, plant foods, including vegetables, fruit, wheat, rice, and barley, have been conventionally ingested in many countries around the world due to their nutritional support for the body. Moreover, plant foods contain naturally occurring bioactive components known as phytochemicals. Therefore, plants are a source of safe, healthy foods because they are suitable for long-term use, although the fact that ingesting plants might have therapeutic benefits is clearly not a new concept. Specifically, functional foods, and their bioactive compounds that play a role in improving skeletal health, have received noticeable attention. Recently, a number of studies have reported that functional foods and their phytochemicals prevent bone loss in both female and male osteoporotic animal models, as well as in postmenopausal women [12-15]. Therefore, dietary intake of natural bioactive plant foods is an adaptable habit that may play a key role in reducing the risk of diseases disorders, such as osteoporosis.

The various physiological functions of barley have been reported to exhibit antioxidative, anti-inflammatory, antiobesity, hair-growth stimulation, and cholesterol-lowering activities [16-21]. These studies have attracted considerable research attention focusing on the biological activity of barley, and its evident safety valuation has accelerated the commercial use of barley and its phytochemicals. Furthermore, researchers have shown an interest in developing natural ingredients that can increase the bioactive components in barley. Notably, the barley seedling (BS), grown for about 7 days from barley seed, contains high concentrations of various physiologically active ingredients that enable it to germinate and to protect itself from external attacks. In particular, BS contains policosanols with substantial levels of polyphenol and saponarin as a major flavonoid, which have a variety of biological activities [22, 23]. Accordingly, the pharmaceutical properties of BS have potential roles in the prevention and treatment of disease. Few studies have investigated barley seedling extracts (BSE), and it has not been elucidated as to whether or not BSE has antiresorptive activity. Therefore, we investigated the effect of BSE on RANKL-mediated osteoclast differentiation and the boneresorbing activity of mature osteoclasts.

\section{Materials and Methods}

2.1. Preparation of the Barley Seedling Extracts. Barley (Hordeum vulgare L.) was cultivated in 2015 in the experimental field at the National Institute of Crop Science, Rural Development Administration, Jeonbuk, Korea. BS was prepared using the procedure reported in the literature [23]. Barley seeds were washed twice using deionized distilled water and imbibed in water at $18^{\circ} \mathrm{C}$ for $24 \mathrm{hr}$. The imbibed seeds were germinated in $65 \%$ humidity at $16^{\circ} \mathrm{C}$ in a normal light cycle (16/8 hr day/night). The germinating seeds and seedlings were harvested in liquid nitrogen 7 days after germination. The collected leaves were freeze-dried immediately after sampling. Prior to obtaining the BSE, the leaves were pulverised to 100 mesh. The masses of all the samples were based on dry weight. To determine the antiosteoporotic activities, the pulverised seeds $(10 \mathrm{~g})$ were extracted with $20 \mathrm{ml}$ of the prethanol for 2 days at $4^{\circ} \mathrm{C}$ in the dark. The crude extracts were filtered through Whatman Number 42 filter paper to remove the sediment. The solvent was evaporated, and the prethanol extracts were obtained from the BS.

2.2. Reagents and Antibodies. Mouse soluble RANKL and MCSF were purchased from R\&D Systems (Minneapolis, MN, USA). Penicillin, streptomycin, cell culture medium, and foetal bovine serum (FBS) were purchased from Invitrogen Life Technologies (Carlsbad, CA, USA). Antibodies against NFATcl, actin, and $\mathrm{I} \kappa \mathrm{B}$ and secondary antibody conjugated to horseradish peroxidase (HRP) were purchased from Santa Cruz Biotechnology (Dallas, TX, USA). All of the other antibodies were obtained from Cell Signaling Technology (Beverly, MA, USA).

2.3. Ethics Statement. This study was conducted in strict accordance with the recommendations in the Standard Protocol for Animal Study of Gangnam Severance Hospital Biomedical Center (Permit Number 2016-0238). The protocol (ID Number 0238) was approved by the Institutional Animal Care and Use Committee (IACUC) of Yonsei University College of Medicine. Every effort was made to minimise the number of animals used in the study and minimise their suffering and stress/discomfort.

2.4. Preparation of Osteoclast Precursor Cells. All the experiments were carried out as described in a previous study, with modifications [24]. Five-week-old male Imprinting Control Region (ICR) mice (Damul Science Co., Daejeon, Korea) were maintained in a room illuminated daily from 07:00 to 19:00 (12:12 hr light/dark cycle), with controlled temperature $\left(23 \pm 1^{\circ} \mathrm{C}\right)$ and ventilation (10-12 times per hour); humidity was maintained at $55 \pm 5 \%$ and the animals had free access to a standard animal diet and tap water. 
TABLE 1: The primer sequences used in this study.

\begin{tabular}{lcc}
\hline Target gene & Forward primer $\left(5^{\prime}-3^{\prime}\right)$ & Reverse primer $\left(5^{\prime}-3^{\prime}\right)$ \\
\hline$c$-Fos & CCAGTCAAGAGCATCAGCAA & AAGTAGTGCAGCCCGGAGTA \\
NFATc1 & GGGTCAGTGTGACCGAAGAT & GGAAGTCAGAAGTGGGTGGA \\
TRAP & GATGACTTTGCCAGTCAGCA & ACATAGCCCACACCGTTCTC \\
OSCAR & AGGGAAACCTCATCCGTTTG & GAGCCGGAAATAAGGCACAG \\
DC-STAMP & CCAAGGAGTCGTCCATGATT & GGCTGCTTTGATCGTTTCTC \\
Cathepsin $K$ & GGCCAACTCAAGAAGAAAAC & GTGCTTGCTTCCCTTCTGG \\
GAPDH & ACCACAGTCCATGCCATCAC & TCCACCACCCTGTTGCTGTA \\
HPRT1 & TGCTCGAGATGTCATGAAGG & AGAGGTCCTTTTCACCAGCA \\
\hline
\end{tabular}

Bone marrow cells were obtained from the five-week-old male ICR mice by flushing their femurs and tibias with alpha minimum essential medium- $(\alpha$-MEM-) containing antibiotics (100 units/ml penicillin, $100 \mu \mathrm{g} / \mathrm{ml}$ streptomycin). The bone marrow cells were cultured on culture dishes for 1 day in $\alpha$-MEM containing $10 \%$ FBS and M-CSF $(10 \mathrm{ng} / \mathrm{ml})$. The nonadherent bone marrow cells were plated into Petri dishes and cultured for 3 days in the presence of $\mathrm{M}$ CSF $(30 \mathrm{ng} / \mathrm{ml})$. After the nonadherent cells were washed out, the adherent cells were used as bone marrow-derived macrophages (BMMs).

2.5. Osteoclast Cell Culture and Osteoclast Differentiation. The BMMs were maintained in $\alpha$-MEM supplemented with $10 \%$ FBS, 100 units $/ \mathrm{ml}$ penicillin, and $100 \mu \mathrm{g} / \mathrm{ml}$ streptomycin. The medium was changed every 3 days in a humidified atmosphere of $5 \% \mathrm{CO}_{2}$ at $37^{\circ} \mathrm{C}$. To differentiate the osteoclasts from the BMMs, the BMMs $\left(1 \times 10^{4}\right.$ cells/well in a 96 -well plate or $3 \times 10^{5}$ cells/well in a 6 -well plate) were cultured with M-CSF $(30 \mathrm{ng} / \mathrm{ml})$ and RANKL $(10 \mathrm{ng} / \mathrm{ml})$ for 4 days, and then the multinucleated osteoclasts were observed.

2.6. TRAP Staining and Activity Assay. The mature osteoclasts were visualised using TRAP staining, a biomarker of osteoclast differentiation. Briefly, the multinucleated osteoclasts were fixed with $3.7 \%$ formalin for $10 \mathrm{~min}$, permeabilised with $0.1 \%$ Triton X-100 for $10 \mathrm{~min}$, and then stained with TRAP solution (Sigma-Aldrich, Saint Louis, MO, USA). The TRAP-positive multinucleated osteoclasts (MNC; nuclear $\geq 3$ or nuclear $\geq 10$ ) were counted. To measure TRAP activity, the multinucleated osteoclasts were fixed in $3.7 \%$ formalin for $5 \mathrm{~min}$, permeabilised with $0.1 \%$ Triton X-100 for $10 \mathrm{~min}$, and then treated with TRAP buffer (100 mM sodium citrate, $\mathrm{pH} 5.0,50 \mathrm{mM}$ sodium tartrate) containing $3 \mathrm{mM}$ p-nitrophenyl phosphate (Sigma-Aldrich) at $37^{\circ} \mathrm{C}$ for $5 \mathrm{~min}$. The reaction mixtures in the wells were transferred to new plates containing an equal volume of $0.1 \mathrm{~N} \mathrm{NaOH}$, and the optical density values were determined at $405 \mathrm{~nm}$.

2.7. Cell Viability Assay. The BMMs were plated in a 96well plate at a density of $1 \times 10^{4}$ cells/well, in triplicate. After treatment with M-CSF (30 ng/ml) and various concentrations of BSE, the cells were incubated for 3 days, and cell viability was measured using the Cell Counting Kit 8 (CCK-8) according to the manufacturer's protocol. The CCK- 8 assay kit was purchased from Dojindo Molecular Technologies (Rockville, MD, USA).

2.8. RNA Isolation and Real-Time Polymerase Chain Reaction Analysis. Real-time polymerase chain reaction (PCR) was performed as described previously [25]. The primers were chosen using the online Primer3 design program [26]. The primer sets used in this study are shown in Table 1. Briefly, total RNA was isolated with TRIzol reagent, and the firststrand cDNA was synthesized with the RevertAid FirstStrand cDNA Synthesis Kit (Thermo Scientific, Waltham, MA, USA) according to the manufacturer's recommended protocol. SYBR green-based quantitative PCR (qPCR) was performed using the Bio-Rad CFX96 Real-Time PCR Detection System (Hercules, CA, USA) and Topreal qPCR 2x PreMIX (Enzynomics, Daejeon, Korea). All reactions were run in triplicate, and the data were analysed using the $2^{-\Delta \Delta C T}$ method [27]. Hypoxanthine phosphoribosyltransferase 1 (HPRT1) and glyceraldehyde 3-phosphate dehydrogenase (GAPDH) were used as the internal standard genes. The statistical significance was determined using Student's t-test with HPRT1/GAPDH-normalised $2^{-\Delta \Delta C T}$ values; the differences were considered significant at $P<0.05$.

2.9. Western Blot Analysis. Western blot analysis was performed as described previously [28]. Briefly, the cultured cells were washed with ice-cold phosphate-buffered saline (PBS) and lysed in lysis buffer (50 mM Tris- $\mathrm{HCl}, 150 \mathrm{mM}$ $\mathrm{NaCl}, 5 \mathrm{mM}$ EDTA, 1\% Triton X-100, $1 \mathrm{mM}$ sodium fluoride, $1 \mathrm{mM}$ sodium vanadate, and $1 \%$ deoxycholate) supplemented with protease inhibitors. After centrifugation at $15,000 \times \mathrm{g}$ for $15 \mathrm{~min}$, the protein quantification in the supernatant was determined using the detergent compatible (DC) protein assay kit (Bio-Rad). The quantified proteins were denatured, separated on sodium dodecyl sulphate-polyacrylamide gel electrophoresis (SDS-PAGE) gels, and transferred onto a polyvinylidene difluoride (PVDF) membrane (Merck Millipore, Darmstadt, Germany). After incubation with an antibody, the membranes were developed using SuperSignal West Femto Maximum Sensitivity Substrate (Thermo Scientific) and visualised with the LAS-4000 luminescent image 
analyser (GE Healthcare Life Sciences, Little Chalfont, UK). Actin was used as a loading control.

2.10. Bone Pit Formation Analysis. The mature osteoclasts were prepared by isolating osteoblasts from the calvariae of newborn mice by serial digestion in $0.1 \%$ collagenase (Gibco, Paisley, UK), as previously described [29]. The bone marrow cells were isolated as described above. The osteoblasts $\left(3.5 \times 10^{5}\right.$ cells/well $)$ and BMMs $\left(1 \times 10^{6}\right.$ cells/well $)$ were cocultured on a collagen-coated $90 \mathrm{~mm}$ dish in the presence of $1 \alpha, 25$-dihydroxyvitamin $\mathrm{D}_{3}\left(\mathrm{VitD}_{3}\right)$ and prostaglandin $\mathrm{E}_{2}\left(\mathrm{PGE}_{2}\right)$ for 6 days. The $\alpha$-MEM complete medium with $\mathrm{VitD}_{3}$ and $\mathrm{PGE}_{2}$ was changed every 3 days. The cocultured cells were detached from the collagen-coated dishes using $0.1 \%$ collagenase and then replated on a bone biomimetic synthetic surface (Corning, NY, USA) in a 24-well plate. After $1 \mathrm{hr}$, each well was treated with RANKL $(10 \mathrm{ng} / \mathrm{ml})$ and BSE for $24 \mathrm{hrs}$. The cells on these plates were stained for TRAP and photographed under a light microscope at $10 \mathrm{x}$ magnification. To observe the resorption pits, the slides were washed with PBS and treated with 5\% sodium hypochlorite for $5 \mathrm{~min}$. After the plate was washed with PBS and dried, it was photographed under a light microscope. Quantification of the resorbed areas was performed using the ImageJ program.

2.11. Statistical Analysis. All quantitative values are presented as mean \pm standard deviation. Each experiment in triplicate was performed three to five times, and Figures 1-5 show the results from one representative experiment. Statistical differences were analysed using Student's $t$-test, and a value of $P<0.05$ was considered significant.

\section{Results}

3.1. BSE Inhibits RANKL-Induced Osteoclast Differentiation. To determine the effect of BSE on RANKL-mediated osteoclastogenesis, the BMMs were incubated with different concentrations of BSE followed by RANKL (10 ng/ml) treatment. The BMMs induced numerous TRAP-positive multinucleated osteoclast cells (TRAP+ MNCs) by RANKL in the control group (vehicle treatment), but BSE attenuated the formation of TRAP+ MNCs in a dose-dependent manner (Figure 1(a)). The inhibitory effect was confirmed by counting the number of TRAP+ MNCs (Figure 1(b); left panel) and measuring TRAP activity (Figure 1(b); right panel). Since the cellular cytotoxicity of BSE in the survival of the BMMs could affect RANKL-induced osteoclast differentiation, its effect was examined using the CCK-8 assay. As shown in Figure 1(c), no cytotoxicity of BSE was observed at the indicated dose. These results show that BSE significantly inhibited RANKL-mediated osteoclast differentiation without apparent cytotoxicity.

3.2. BSE Attenuates RANKL-Induced Expression of c-Fos and NFATc1 during Osteoclastogenesis. The inhibitory effect of BSE on osteoclast differentiation was examined by evaluating the expression level of several osteoclastogenesisassociated genes, including transcriptional factors. As shown in Figure 2(a), the mRNA expression levels of osteoclastogenesis-related transcription factors, such as c-Fos and NFATc1, were induced by RANKL, but these inductions were significantly inhibited by treatment with BSE. In addition, BSE also strongly attenuated the mRNA induction of c-Fos/NFATcl-dependent molecules, such as TRAP and OSCAR. Western blot analysis further revealed that the RANKL-induced translational expression of both c-Fos and NFATcl was strongly inhibited by treatment with BSE (Figure 2(b)). Taken together, these results suggest that the antiosteoclastogenesis activity of BSE could arise from its potential to inhibit the expression of c-Fos/NFATc1, the early-stage transcription factor that is required for osteoclast differentiation.

3.3. BSE Contributes to RANKL-Mediated NF- $\kappa B / I \kappa B$ Signaling Pathways. To clarify the mode of antiosteoclastic action by BSE, we investigated whether or not BSE could affect the activation of the RANKL-mediated signaling molecules associated with the regulation of c-Fos/NFATcl expression, which are master transcription factors required for osteoclast differentiation. As shown in Figure 3, RANKL stimulated degradation of $\mathrm{I} \kappa \mathrm{B}$ and the activation of RAC-Alpha Serine/Threonine-Protein Kinase (AKT) and MAP kinases, including extracellular signal-regulated kinase (ERK), c-Jun N-terminal kinase (JNK), and p38, but BSE only blocked the RANKL-induced degradation of $\mathrm{I} \kappa \mathrm{B}$. These results demonstrate that attenuation of $\mathrm{I} \kappa \mathrm{B}$ degradation could be involved in the antiosteoclastogenic action of BSE.

3.4. BSE Inhibits Osteoclast Differentiation in the Late Stage Associated with Cell Fusion as well as in the Early Stages. To better understand when BSE inhibits osteoclast differentiation, we examined the antiosteoclastogenic activity of BSE by treating the cells at four time points, as shown in Figure 4(a). Treatment with BSE for $24 \mathrm{hrs}$ moderately inhibited the RANKL-induced formation of TRAP+ MNCs in the early-to-late stages of osteoclastogenesis (Figure 4(b)). Moreover, TRAP activity was also attenuated by the addition of BSE (Figure 4(c)). Interestingly, the presence of BSE $(3 \mu \mathrm{g} / \mathrm{ml})$ from day 3 to day 4 dramatically repressed TRAP+ MNCs formation with $>10$ nuclei giant osteoclasts (Figure 4(b), 3-4d) and reduced the number of fused cells (Figure $4(\mathrm{~d})$ ). We confirmed the inhibitory effect of BSE on the monocyte TRAP+ cells into giant multinucleated osteoclasts by evaluating the mRNA expression level of DCSTAMP, which is an essential factor for osteoclast fusion. BSE strongly inhibited the RANKL-induced mRNA expression of DC-STAMP (Figure 4(e)). These results indicate that the antiosteoclastogenic effect of BSE could be due to its potential to inhibit multistep response in the early, middle, and late stages of osteoclast differentiation.

3.5. BSE Prevents the Bone-Resorbing Function of Mature Osteoclasts. Next, to investigate whether BSE has the potential to inhibit the survival and the bone-resorbing activity of mature osteoclasts, we performed resorption-related gene expression, mature osteoclast counting, and a bone pit formation assay. As shown in Figure 5(a), BSE significantly 


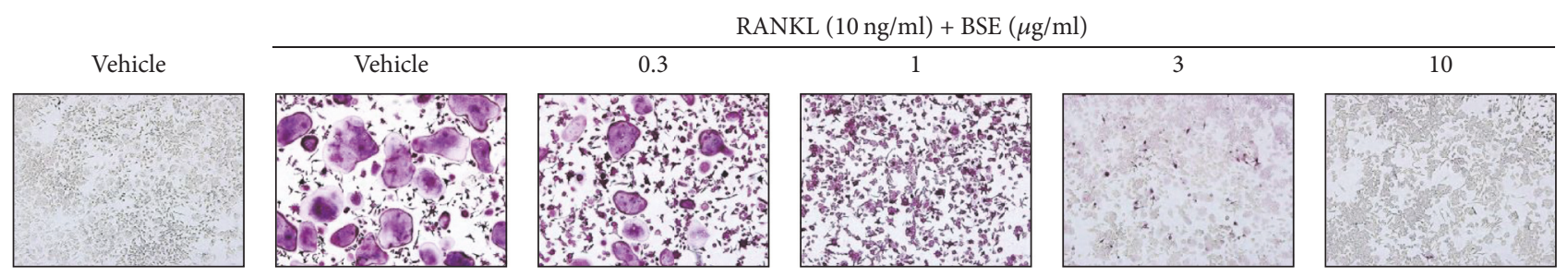

(a)
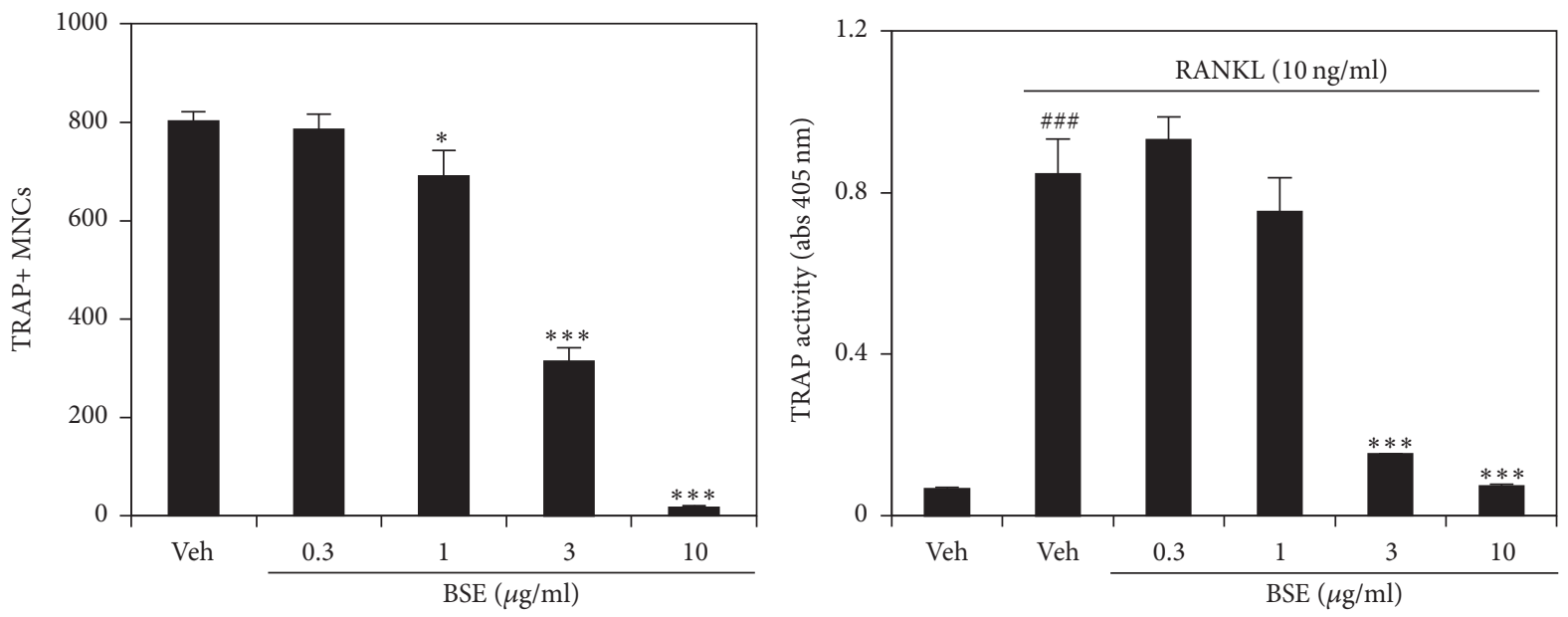

(b)

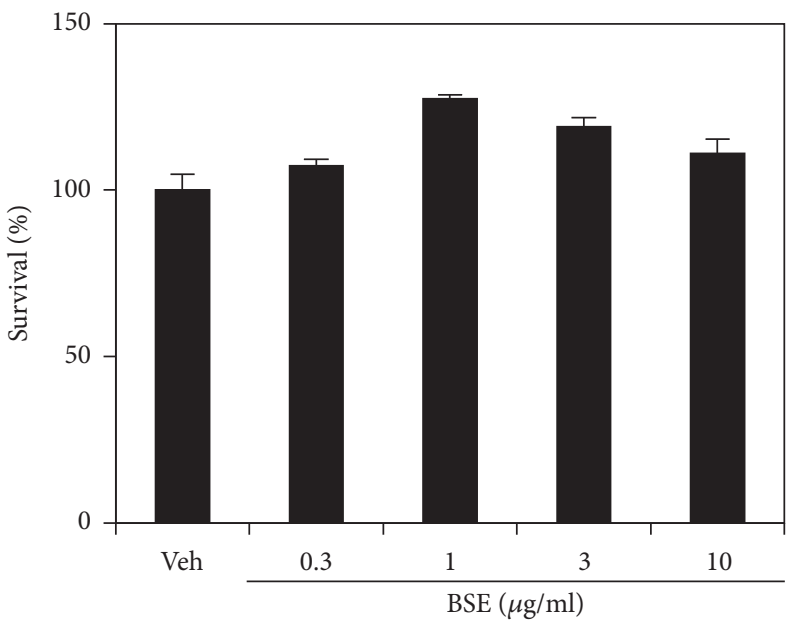

(c)

FIGURE 1: BSE impairs RANKL-induced osteoclast differentiation. (a) The BMMs were cultured for 4 days in the presence of RANKL $(10 \mathrm{ng} / \mathrm{ml})$ and M-CSF $(30 \mathrm{ng} / \mathrm{ml})$ with either the vehicle (prethanol) or the indicated concentration of BSE. Multinucleated osteoclasts were visualised using TRAP staining. (b) TRAP+ MNCs were counted (left panel) and TRAP activity was measured (right panel). ${ }^{\# \# \# ~}<0.001$ (versus the control); ${ }^{*} P<0.05 ;{ }^{* * *} P<0.001$ (versus the RANKL-treated group). (c) The effect of BSE on the viability of BMMs was evaluated using the CCK- 8 assay. Data are expressed as mean \pm SD and are representative of at least three experiments.

inhibited the RANKL-mediated mRNA induction of cathep$\sin \mathrm{K}$, which plays a role in bone resorption. We then confirmed the effect of BSE on the RANKL-induced bone resorptive function of mature osteoclasts in a coculture system of BMMs and primary osteoblast cells. When the purified mature osteoclasts from the coculture were replated on a bone biomimetic synthetic surface and cultured with/without BSE for 1 day, no significant difference was observed between the BSE-treated cells and the control group in terms of TRAP+ MNCs formation (Figure 5(b); upper panel) and the number of TRAP+ MNCs (Figure 5(c)). However, the addition of BSE strongly inhibited the areas of resorption formation (Figure 5(b); bottom panel) as measured using the resorbing bone pit assay (Figure 5(d)). These results revealed that 


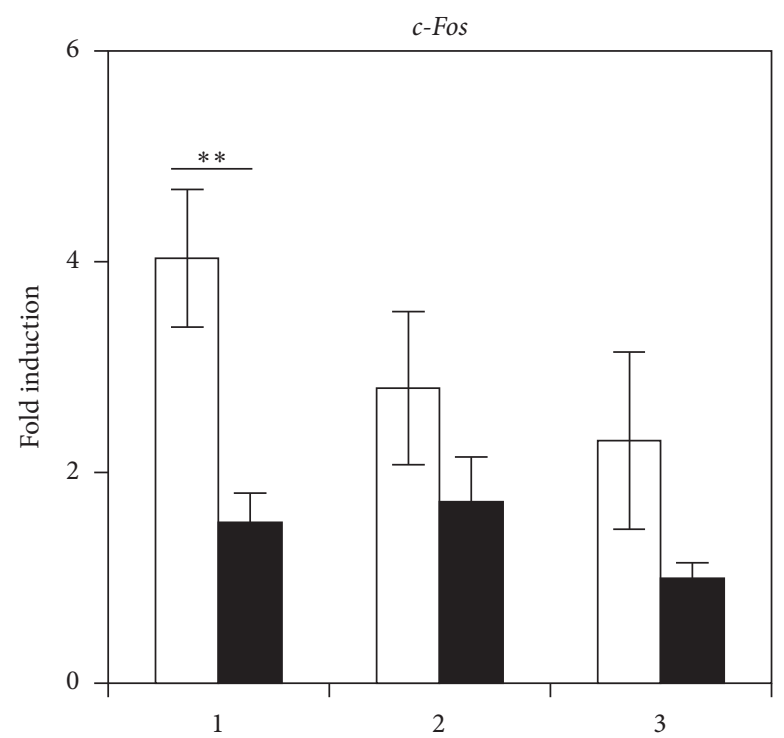

(d)

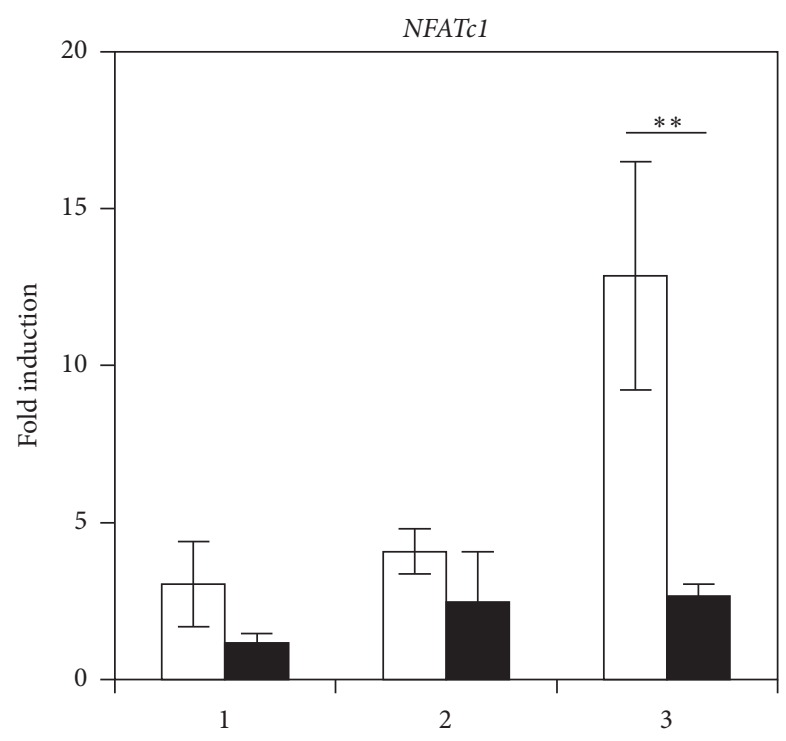

(d)

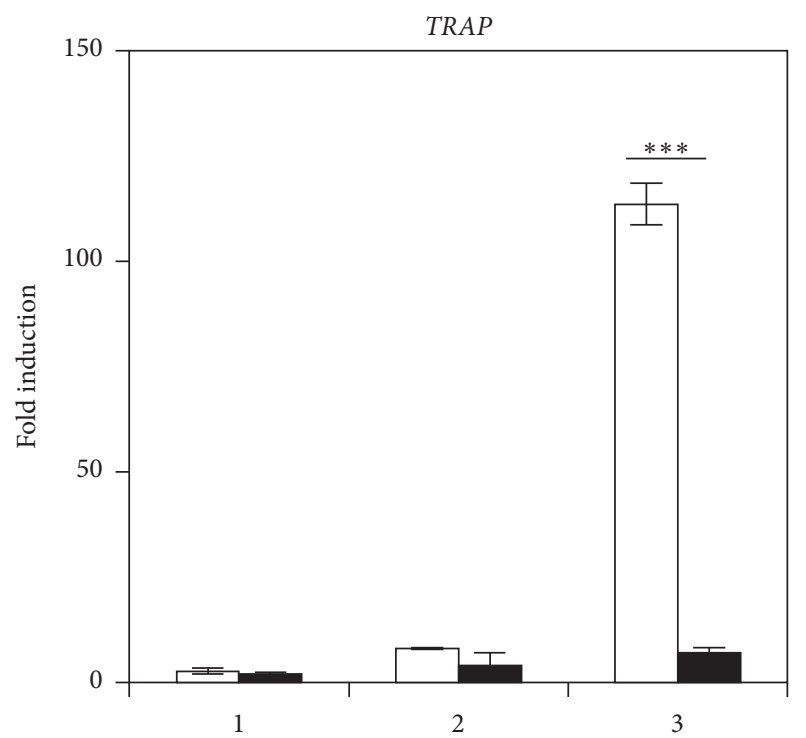

(d)

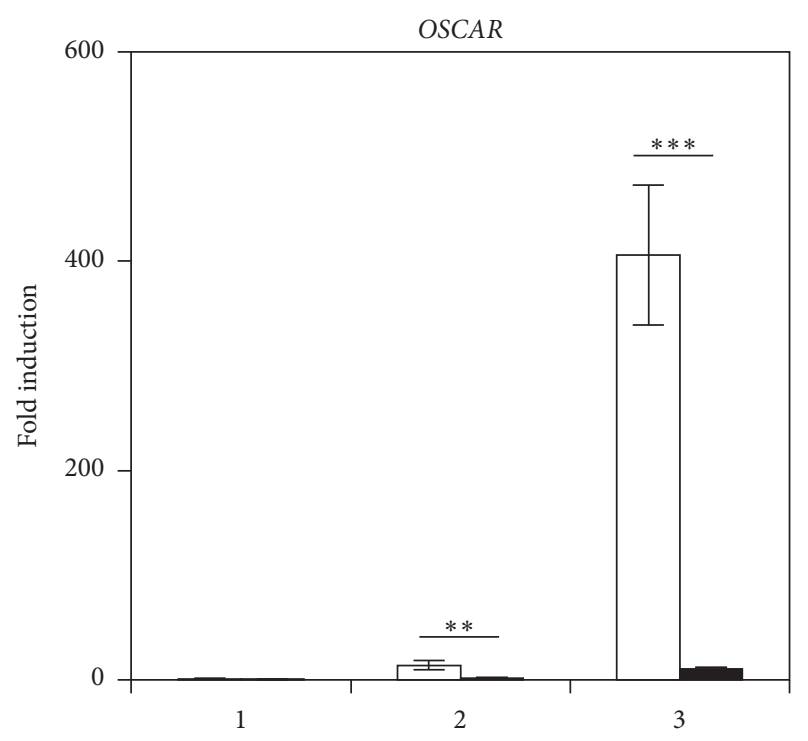

(d)

Vehicle

BSE $(3 \mu \mathrm{g} / \mathrm{ml})$

$\square$ Vehicle

$\operatorname{BSE}(3 \mu \mathrm{g} / \mathrm{ml})$

(a)
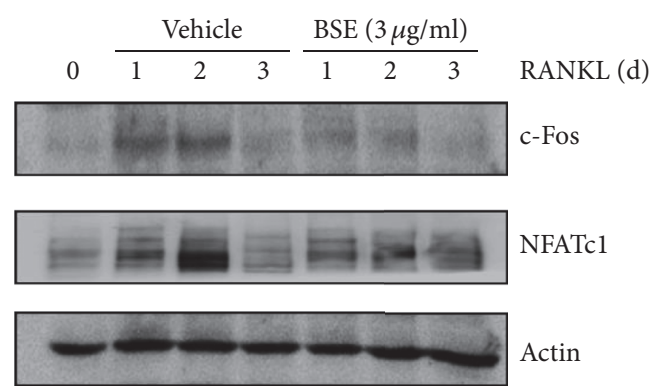

(b)

FIgURE 2: BSE inhibits the RANKL-mediated expression level of c-Fos/NFATcl. (a) The BMMs were stimulated with RANKL (10 ng/ml) and M-CSF $(30 \mathrm{ng} / \mathrm{ml})$ in the presence or absence of BSE $(3 \mu \mathrm{g} / \mathrm{ml})$ for the indicated times. Total RNA was then isolated using TRIzol reagent, and the mRNA expression levels were evaluated using real-time PCR. GAPDH was used as the internal control. ${ }^{* *} P<0.01$; ${ }^{* * *} P<0.001$ (versus the vehicle control). (b) The effect of BSE on the protein expression level of RANKL-induced transcription factors was evaluated using Western blot analysis. Actin was used as the internal control. Data are representative of at least three experiments. 


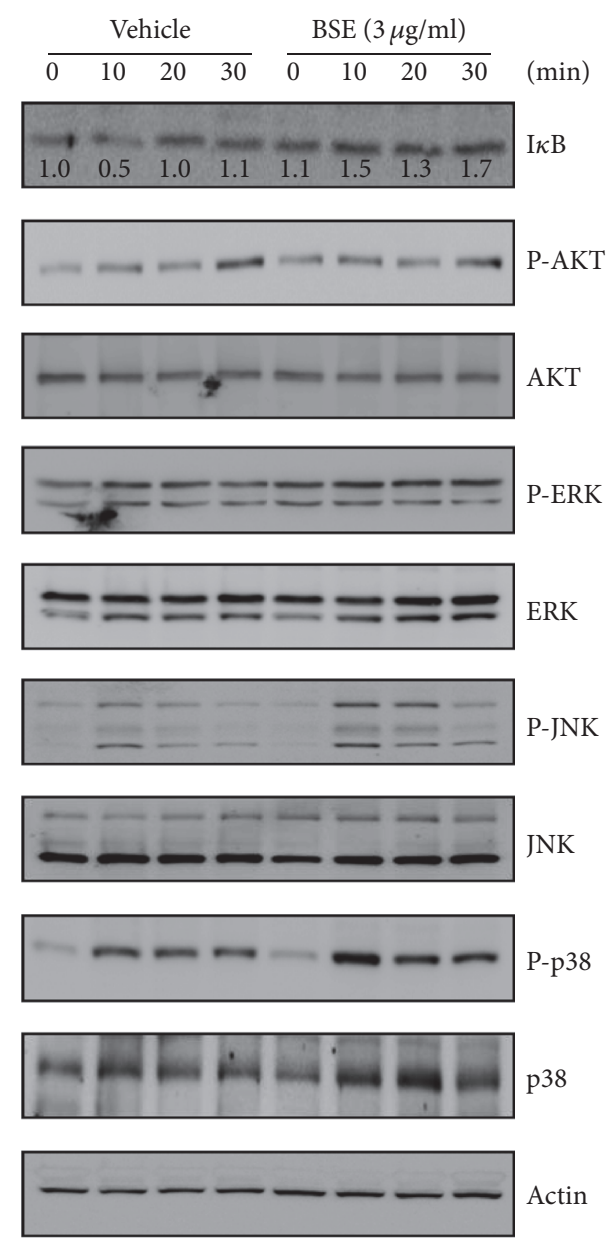

FIGURE 3: BSE attenuates RANKL-induced degradation of $\mathrm{I} \kappa \mathrm{B}$ signaling molecules. In the condition of serum starvation for $1 \mathrm{hr}$, the BMMs were pretreated with or without BSE $(3 \mu \mathrm{g} / \mathrm{ml})$ for $1 \mathrm{hr}$ prior to RANKL stimulation $(10 \mathrm{ng} / \mathrm{ml})$ at the indicated time periods. Then, the expression levels of the signaling molecules were evaluated using Western blot analysis. The indicated densitometric values were obtained using Multi Gauge version 3 software. One representative result obtained from three independent experiments yielding similar results is shown.

BSE could prevent the bone resorptive function of mature osteoclasts without any alterations in the cell survival of the giant multinucleated osteoclasts.

\section{Discussion}

Antiosteoclastic agents have become the therapeutic mainstay for treating osteoporosis. However, the most common antiresorptive agents, such as bisphosphonates, also carry the risk of side effects, such as bisphosphonate-mediated osteonecrosis of the jaw [30] and atypical femoral fractures [31]. Consequently, the use of antiosteoclastic agents is limited due to concerns about their long-term safety. Therefore, new, safe therapeutic agents are urgently needed for the longterm management of bone disease.
Plant-based natural products have traditionally yielded a variety of therapeutic agents. Generally, healthy nutrients or foods with pharmaceutical properties are both effective and safe for the long-term administration of a variety of disorders. Recently, studies have attempted to identify natural products or healthy foods that can prevent and/or treat osteoporosis with minimal adverse effects [32].

As a major food crop for humans, barley is the second most commonly consumed grain in Korea, and it is recognised as a safe and healthy food to consume. Several studies have shown that BSE and its components exhibit antioxidant activities, decrease blood glucose and cholesterol levels, and protect against liver injury [33-36]. Nonetheless, the antiresorptive activity and mode of action of BS in bone metabolic diseases have not been revealed. This current study is the first to report on the antiosteoclastogenesis and inhibition of bone-resorbing activity of BSE.

The differentiation of osteoclasts from hematopoietic stem cells in bone marrow is specifically regulated by RANKL [37]. RANKL signaling triggers osteoclast formation, which is considered to be an important target for preventing pathological bone loss. In this study, BSE attenuated the RANKL-related differentiation of BMMs into osteoclasts in a dose-dependent manner without any cytotoxicity in concentrations up to $10 \mu \mathrm{g} / \mathrm{ml}$.

RANKL stimulates transcription factors, such as c-Fos and NFATc1, during osteoclast differentiation. As activator protein-1 (AP-1) family members, c-Fos and NFATc1 play a major role in the regulation of molecules for osteoclast differentiation. An important role for c-Fos in the process of osteoclast differentiation has been clarified in c-Fos knockout mice [38]. The c-Fos-deficient mice had osteopetrosis due to a cell-autonomous defect in osteoclast differentiation [39]. Furthermore, Takayanagi et al. [40] reported that NFATc1deficient embryonic stem cells do not differentiate into mature osteoclasts, even in the presence of RANKL. As major transcription factors, c-Fos and NFATcl are also functionally linked together. Particularly, c-Fos is essential for RANKLinduced expression of NFATcl. c-Fos is expressed in the early stages of osteoclast differentiation, and it regulates NFATcl gene expression by binding to the promoter region of NFATcl [40]. NFATcl is expressed in the middle or late stages of osteoclastogenesis, and it regulates osteoclast-mediated genes, such as TRAP, and OSCAR [9, 41]. Therefore, cFos and NFATc1 are master regulators for RANKL-induced osteoclast differentiation. In this study, two transcription factors such as c-Fos and NFATcl inhibited the expression of the transcriptional and translational levels by BSE treatment during osteoclast differentiation. In addition, the inhibitory effect of BSE via downregulation of c-Fos and NFATc1 was confirmed by evaluating the transcriptional expression levels of c-Fos/NFATcl-dependent genes, such as TRAP and OSCAR. These results suggest that c-Fos/NFATc1, as a main transcriptional marker of osteoclastogenesis, is involved in BSE's inhibitory effect on osteoclast differentiation.

The binding of RANKL to its receptor RANK activates various signaling pathways, including $\mathrm{NF}-\kappa \mathrm{B}, \mathrm{PI} 3 \mathrm{~K} / \mathrm{AKT}$, and MAP kinases, consisting of p38, ERK, and JNK, in the early stage of osteoclastogenesis [37, 42]. It is known that 


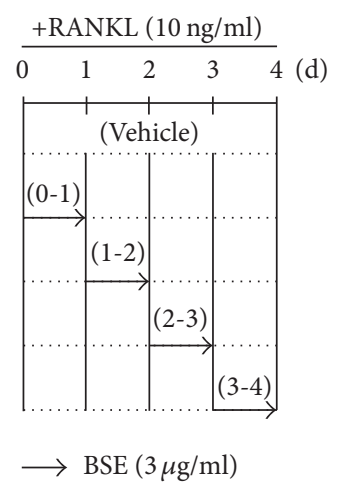

(a)
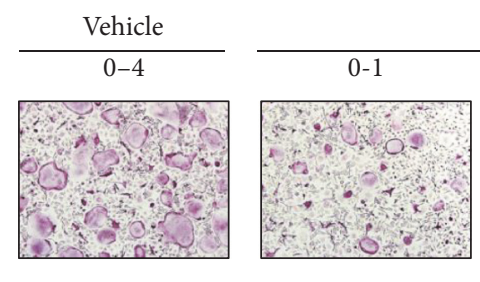

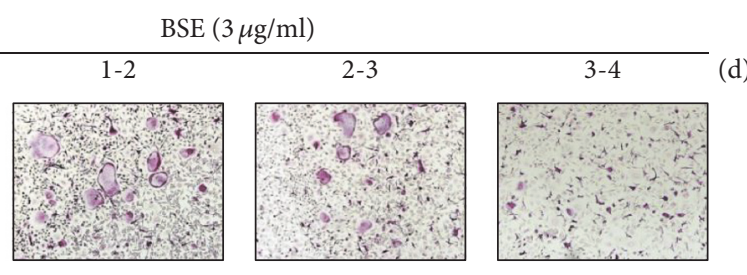

(b)

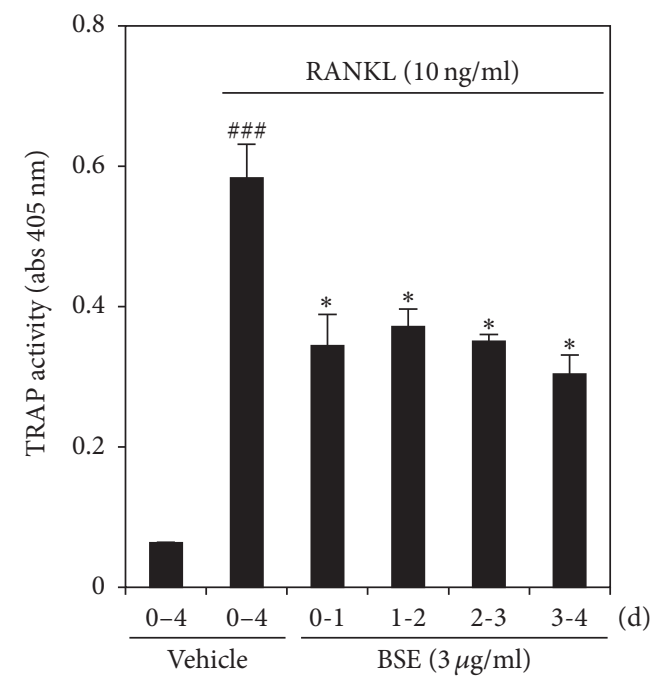

(c)

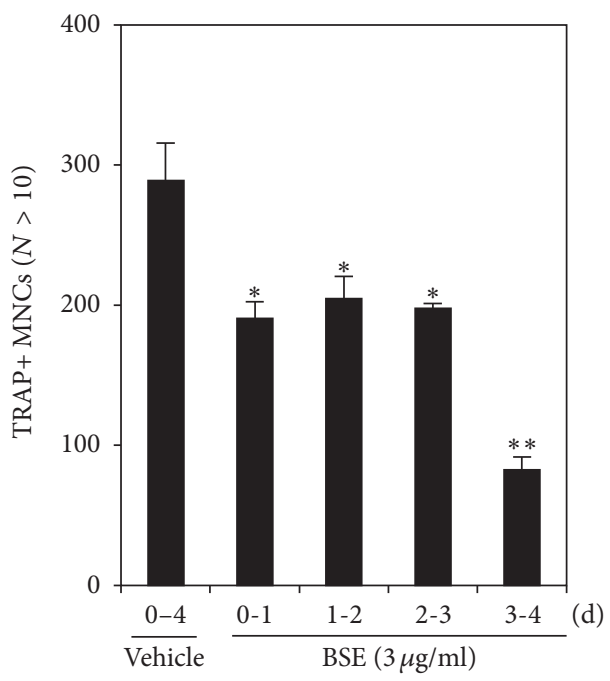

(d)

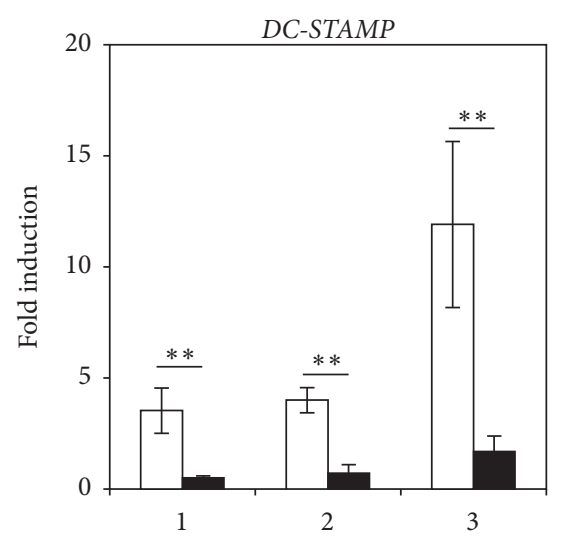

(d)

Vehicle

$\operatorname{BSE}(3 \mu \mathrm{g} / \mathrm{ml})$

(e)

Figure 4: BSE also inhibits RANKL-mediated cell fusion during osteoclastogenesis. (a) Based on the exposure schedule, the BMMs were cultured with BSE ( $3 \mathrm{ug} / \mathrm{ml}$ ) for various times periods (the indicated black arrow) in the presence of $\mathrm{M}-\mathrm{CSF}(30 \mathrm{ng} / \mathrm{ml}) \mathrm{and} \mathrm{RANKL}(10 \mathrm{ng} / \mathrm{ml})$. (b) After the BMMs differentiated into osteoclasts (as described in (a)), the cells were fixed, permeabilised, and stained with TRAP. TRAP+ MNCs formation was photographed under a light microscope. Each exposure period of BSE was indicated as "0-4" for the vehicle. " $0-1$ " for 01 day, "1-2" for 1-2 days, "2-3" for 2-3 days, and “3-4" for 3-4 days. (c) TRAP activity was measured at 405 nm. ${ }^{\# \# ~} P<0.001$ (versus the control); ${ }^{*} P<0.05$ (versus the RANKL-treated control). (d) The number of TRAP+ MNCs (nuclei $>10$ ) was counted. ${ }^{*} P<0.05$; ${ }^{* *} P<0.01$ (versus the RANKL-treated group). (e) The effect of BSE on the mRNA expression of DC-STAMP was analysed using real-time PCR, as described in Figure 2(a). HPRT was used as the internal control. White column (vehicle-treated); black column $\left(3 \mu \mathrm{g} / \mathrm{ml} \mathrm{BSE-treated)},{ }^{* *} P<0.01\right.$ (versus the vehicle control). Data are representative of at least three experiments. 

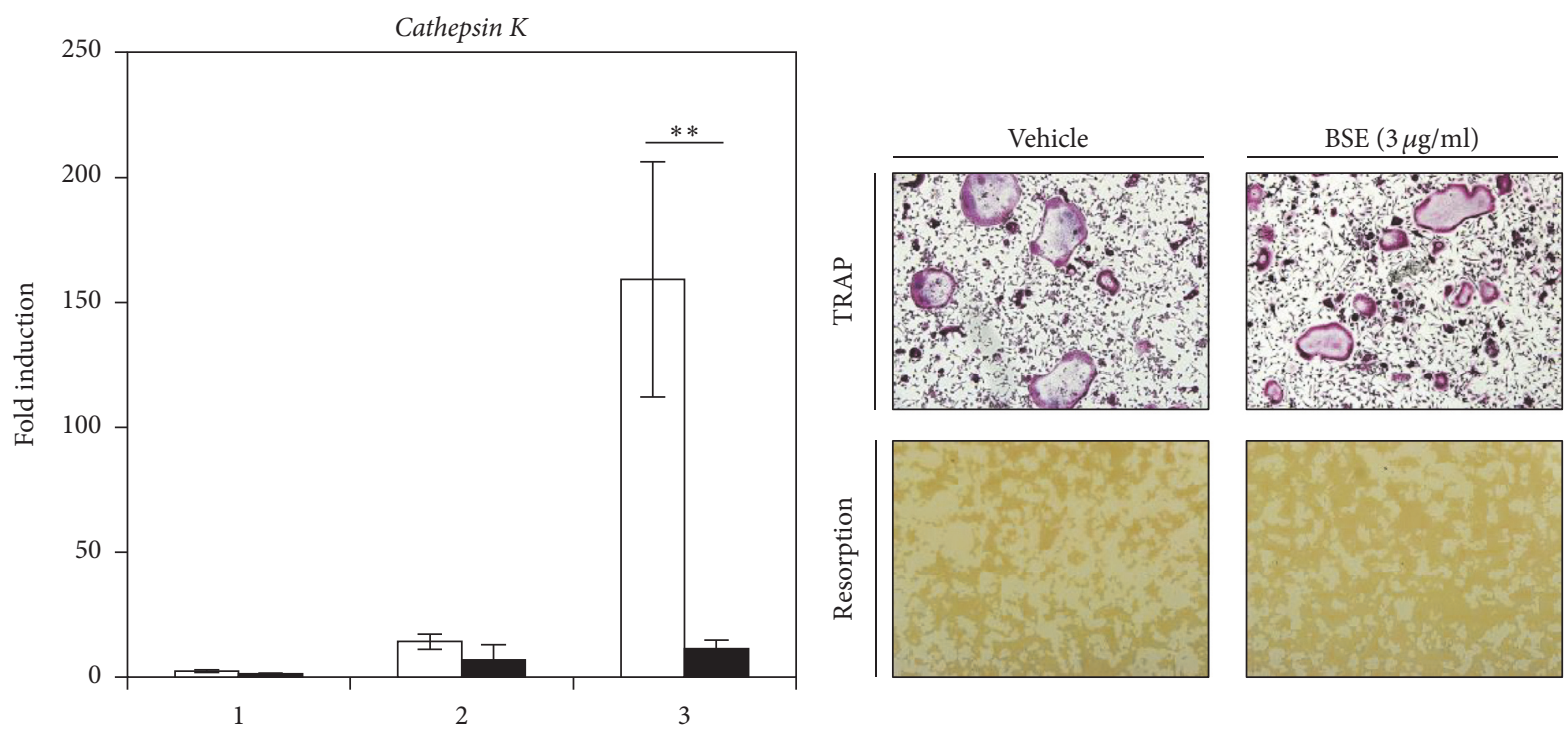

(d)
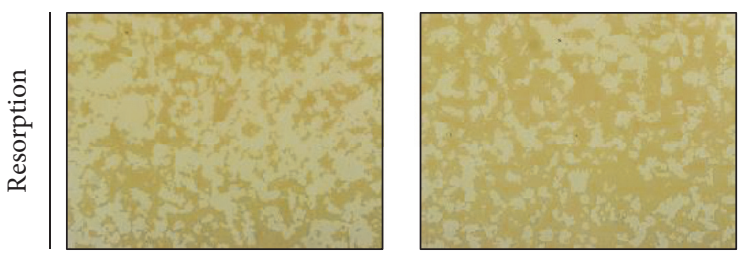

Vehicle

BSE $(3 \mu \mathrm{g} / \mathrm{ml})$

(a)

(b)
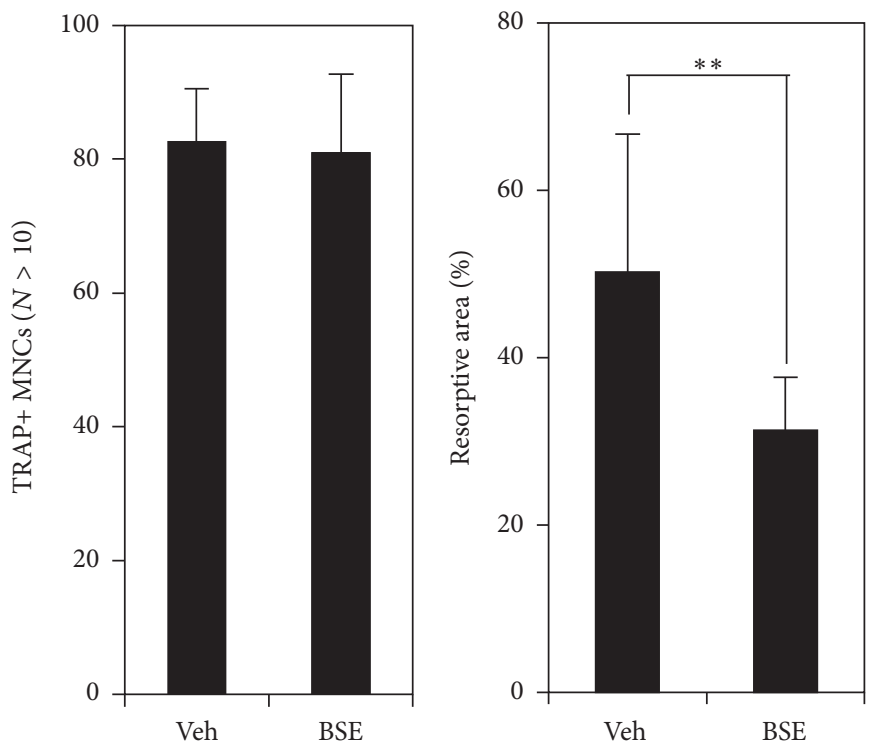

(c)

(d)

FIGURE 5: BSE impairs the osteoclastic function of giant multinucleated cells. (a) The mRNA expression of cathepsin K was evaluated during osteoclast differentiation in the absence or presence of BSE $(3 \mu \mathrm{g} / \mathrm{ml})$ using real-time PCR. The relative fold change of the mRNA expression level is presented in comparison to the control (no RANKL-treated). HPRT was used as the internal control. ${ }^{* *} P<0.01$ (versus the vehicle control). (b) The mature osteoclasts were plated on bone biomimetic synthetic surface and treated for $24 \mathrm{hrs}$ with BSE ( $3 \mu \mathrm{g} / \mathrm{ml}$ ). The cells were fixed, permeabilised, and stained with TRAP. TRAP+ MNCs formation was visualised under a light microscope (top images). The resorption areas were removed from the cells and photographed under a light microscope (bottom images). (c-d) The form (as visualised in (b)) was counted as the number of TRAP+ MNCs (nuclei > 10; (c)), and the resorptive areas (\%) were quantified using the ImageJ program (d). ${ }^{* *} P<0.01$ (versus the vehicle control). One representative result achieved from three independent experiments yielding similar results is shown.

the expression of c-Fos/NFATc1 requires assembly of NF$\kappa \mathrm{B}, \mathrm{PI} 3 \mathrm{~K} / \mathrm{AKT}$, and MAP kinase signaling [40, 43-45]. In this present study, the pathways for the PI3K/AKT and MAP kinases were not affected by BSE. However, BSE prevented the alternation of the RANKL-induced degradation of $\mathrm{I} \kappa \mathrm{B}$ signaling molecules, which leads to NF- $\kappa \mathrm{B}$ activation. I $\kappa \mathrm{B}$ is a member of a family of cellular proteins that function to inhibit NF- $\kappa \mathrm{B}$ molecules. I $\kappa \mathrm{B}$ inhibits NF- $\kappa \mathrm{B}$ by 
masking the nuclear localisation signals of NF- $\kappa$ B proteins and keeping them sequestered in an in-active state in the cytoplasm [46]. In IKK-knockout mice, the upstream I $\kappa \mathrm{B}$ die at birth as a result of severe epidermal defects; however, analysis of the embryonic osteoclasts (E18.5 days postcoitus) revealed reduced numbers of multinucleated osteoclasts with altered morphology [47]. Additionally, NF- $\kappa$ B p50/p52 double knockout mice display defects of osteoclast differentiation and severe osteopetrosis because c-Fos/NFATcl was not induced by RANKL [48]. These reports indicated that the NF- $\kappa \mathrm{B} / \mathrm{I} \kappa \mathrm{B}$ signaling pathway could have the potential to regulate osteoclast differentiation through $\mathrm{c}$-Fos/NFATc1 expression. In this present study, the inhibitory effect of BSE on osteoclastogenesis could result from its potential ability to attenuate the NF- $\kappa \mathrm{B} / \mathrm{I} \kappa \mathrm{B}-\mathrm{c}$-fos/NFATcl signaling axis at the early stage of osteoclast differentiation.

Osteoclast differentiation is a multistep progressive process that involves cell proliferation, commitment, migration, fusion, and maturation $[49,50]$. Monocyte/macrophage precursors derived from hematopoietic stem cells in the bone marrow become preosteoclasts that then migrate and fuse to form giant multinucleated osteoclasts. In this regard, we next investigated whether the inhibitory effect of BSE affected some of the stages of osteoclast differentiation. To determine this, we reevaluated the antiosteoclastogenic activity of BSE by treating cells at each osteoclastogenesis stage. Interestingly, the TRAP+ MNCs formation by BSE was suppressed during the early, middle, and late stages of osteoclast differentiation.

Cell-cell fusion is essential for the formation and maturation of multinucleated osteoclasts; this process involves cellular fusion molecules, such as DC-STAMP. In osteoclastogenesis, DC-STAMP has been reported to be essential for cell-to-cell fusion of preosteoclasts, and it is preferentially expressed in the late stage [51-53]. Osteoclasts derived from DC-STAMP-deficient mice were found to abrogate multinucleated osteoclast formation and increase bone mass [54]. Additionally, DC-STAMP contains multiple NFATc1 binding sites in promoter regions, and it is regulated by NFATc1 transcription factor [55]. As mentioned earlier, we found that the mRNA expression levels of DC-STAMP and NFATc1 were inhibited by BSE during osteoclast differentiation. Taken together, these results suggest that BSE with antiosteoclastogenic activity is involved in osteoclast differentiation from the initial phase of osteoclastogenesis to the terminal phase.

Bone resorption is a unique function of osteoclasts, and it plays a central role in the formation of the skeleton and the regulation of its mass, which is involved in the matrix degradation of the organic and inorganic phases of bone [56]. In this progression, active proteases released from osteoclasts into the resorption lacunae are known to be involved in matrix degradation, and it has been reported that cysteine proteinases play a vital role in this process $[57,58]$. Cathepsin $\mathrm{K}$ is a type of lysosomal cysteine protease, such as a proteolytic enzyme, and it is abundantly expressed in mature osteoclasts. It can degrade the protein components of the demineralised bone matrix, most notably type-1 collagen [59-61]. In addition, a study of cathepsin K-deficient mice found impaired bone loss via reduction of bone resorption and an increased bone formation rate in comparison to the control $[62,63]$. RANKL-mediated cathepsin K expression has been shown to be regulated by NFATc1 [64]. Thus, induction of cathepsin $\mathrm{K}$ by NFATc1 is responsible for the degradation of the collagen matrix by osteoclasts. In our present study, the presence of BSE was associated with inhibition of the cathepsin $\mathrm{K}$ expression level and the anti-bone-resorbing activity of mature osteoclasts.

\section{Conclusions}

To the best of our knowledge, this is the first study to have shown the potential of a natural food, such as BSE, to inhibit osteoclast differentiation and bone-resorbing activity in the early-to-late stages of osteoclastogenesis, although additional experiments are needed to substantiate the identification of the pharmaceutical components in BSE for antiosteoclastogenic activity. BSE inhibits RANKL-induced osteoclastogenic activity by preventing $\mathrm{I} \kappa \mathrm{B}$ degradation and c-Fos/NFATc1 expression. Consequently, the alteration of $\mathrm{I} \kappa \mathrm{B} / \mathrm{c}-\mathrm{Fos} / \mathrm{NFATcl}$ could lead to the decreased expression of the genes required for bone-resorbing activity and cell fusion, such as DC-STAMP and cathepsin K. Moreover, BSE prevented the bone-resorbing activity of mature osteoclasts. Finally, our results suggest that the potential antiresorptive property of BSE might be developed as a functional food and pharmacological agent to improve bone health and to treat osteoclast-mediated bone metabolic disorders, including osteoporosis.

\section{Conflicts of Interest}

The authors have declared no conflicts of interest.

\section{Authors' Contributions}

Sik-Won Choi and Shin-Hye Kim contributed equally to this study.

\section{Acknowledgments}

This work was conducted with the support of the Cooperative Research Program for Agriculture Science \& Technology Development (project title: Study of Metabolites and New Materials for Improvement of Lifestyle Related Disease on Rice and Barley, Project no. PJ00925701) of the Rural Development Administration (RDA), Korea.

\section{References}

[1] S. C. Manolagas and A. M. Parfitt, "What old means to bone," Trends in Endocrinology and Metabolism, vol. 21, no. 6, pp. 369374, 2010.

[2] G. A. Rodan and T. J. Martin, "Therapeutic approaches to bone diseases," Science, vol. 289, no. 5484, pp. 1508-1514, 2000.

[3] S. Khosla and B. L. Riggs, "Pathophysiology of age-related bone loss and osteoporosis," Endocrinology and Metabolism Clinics of North America, vol. 34, no. 4, pp. 1015-1030, 2005.

[4] X. Feng and J. M. McDonald, "Disorders of bone remodeling," Annual Review of Pathology, vol. 6, pp. 121-145, 2011. 
[5] E. Chrischilles, T. Shireman, and R. Wallace, "Costs and health effects of osteoporotic fractures," Bone, vol. 15, no. 4, pp. 377386, 1994.

[6] "Osteoporosis prevention, diagnosis, and therapy," JAMA, 2001.

[7] X. Feng, "RANKing intracellular signaling in osteoclasts," IUBMB Life, vol. 57, no. 6, pp. 389-395, 2005.

[8] L. Galibert, M. E. Tometsko, D. M. Andersen, D. Cosman, and W. C. Dougall, "The involvement of multiple tumor necrosis factor receptor (TNFR)-associated factors in the signaling mechanisms of receptor activator of NF- $\kappa \mathrm{B}$, a member of the TNFR superfamily," Journal of Biological Chemistry, vol. 273, no. 51, pp. 34120-34127, 1998.

[9] H. Takayanagi, "Osteoimmunology: shared mechanisms and crosstalk between the immune and bone systems," Nature Reviews Immunology, vol. 7, no. 4, pp. 292-304, 2007.

[10] H. Takayanagi, "Inflammatory bone destruction and osteoimmunology," Journal of Periodontal Research, vol. 40, no. 4, pp. 287-293, 2005.

[11] I. Nakamura, N. Takahashi, E. Jimi, N. Udagawa, and T. Suda, "Regulation of osteoclast function," Modern Rheumatology, vol. 22, no. 2, pp. 167-177, 2012.

[12] S. Hooshmand and B. H. Arjmandi, "Viewpoint: dried plum, an emerging functional food that may effectively improve bone health," Ageing Research Reviews, vol. 8, no. 2, pp. 122-127, 2009.

[13] T.-H. Huang, R. C. Mühlbauer, C.-H. Tang et al., "Onion decreases the ovariectomy-induced osteopenia in young adult rats," Bone, vol. 42, no. 6, pp. 1154-1163, 2008.

[14] X. Zhang, X.-O. Shu, H. Li et al., "Prospective cohort study of soy food consumption and risk of bone fracture among postmenopausal women," Archives of Internal Medicine, vol. 165, no. 16, pp. 1890-1895, 2005.

[15] R. C. Mühlbauer, A. Lozano, A. Reinli, and H. Wetli, "Various selected vegetables, fruits, mushrooms and red wine residue inhibit bone resorption in rats," Journal of Nutrition, vol. 133, no. 11, pp. 3592-3597, 2003.

[16] J. Zhang, X. Xiao, Y. Dong, L. Shi, T. Xu, and F. Wu, "The antiobesity effect of fermented barley extracts with Lactobacillus plantarum dy-1 and Saccharomyces cerevisiae in diet-induced obese rats," Food \& Function, vol. 8, no. 3, pp. 1132-1143, 2017.

[17] S. Gul, S. Ahmed, N. Kifli et al., "Multiple pathways are responsible for anti-inflammatory and cardiovascular activities of Hordeum vulgare L.", Journal of Translational Medicine, vol. 12, no. 1, 2014, article 316 .

[18] K.-C. Choi, J.-M. Hwang, S.-J. Bang et al., "Methanol extract of the aerial parts of barley (Hordeum vulgare) suppresses lipopolysaccharide-induced inflammatory responses in vitro and in vivo," Pharmaceutical Biology, vol. 51, no. 8, pp. 10661076, 2013.

[19] J. G. Shah, B. G. Patel, S. B. Patel, and R. K. Patel, "Antiurolithiatic and antioxidant activity of Hordeum vulgare seeds on ethylene glycol-induced urolithiasis in rats," Indian Journal of Pharmacology, vol. 44, no. 6, pp. 672-677, 2012.

[20] A. Kamimura and T. Takashashi, "Procyanidin B-3, isolated from barley and identified as a hair-growth stimulant, has the potential to counteract inhibitory regulation by TGF- $\beta 1$," Experimental Dermatology, vol. 11, no. 6, pp. 532-541, 2002.

[21] J. R. Lupton, M. C. Robinson, and J. L. Morin, "Cholesterollowering effect of barley bran flour and oil," Journal of the American Dietetic Association, vol. 94, no. 1, pp. 65-70, 1994.

[22] M. J. Park, J.-E. Ra, K. H. Seo et al., "Identification and evaluation of flavone-glucosides isolated from barley sprouts and their inhibitory activity against bacterial neuraminidase," Natural Product Communications, vol. 9, no. 10, pp. 1469-1472, 2014.

[23] W. D. Seo, H. J. Yuk, M. J. Curtis-Long et al., "Effect of the growth stage and cultivar on policosanol profiles of barley sprouts and their adenosine $5^{\prime}$-monophosphate-activated protein kinase activation," Journal of Agricultural and Food Chemistry, vol. 61, no. 5, pp. 1117-1123, 2013.

[24] S.-W. Choi, J.-T. Yeon, B. J. Ryu et al., "Repositioning potential of pak4 to osteoclastic bone resorption," Journal of Bone and Mineral Research, vol. 30, no. 8, pp. 1494-1507, 2015.

[25] J.-T. Yeon, K.-J. Kim, S. W. Chun et al., "KCNK1 inhibits osteoclastogenesis by blocking the Ca2+ oscillation and JNKNFATcl signaling axis," Journal of Cell Science, vol. 128, no. 18, pp. 3411-3419, 2015.

[26] S. Rozen and H. Skaletsky, "Primer3 on the WWW for general users and for biologist programmers," Methods in Molecular Biology, vol. 132, pp. 365-386, 2000.

[27] K. J. Livak and T. D. Schmittgen, "Analysis of relative gene expression data using real-time quantitative PCR and the $2^{-\Delta \Delta C_{T}}$ method," Methods, vol. 25, no. 4, pp. 402-408, 2001.

[28] S. Choi, K. Lee, J. H. Lee et al., "Suppression of Akt-HIF$1 \alpha$ signaling axis by diacetyl atractylodiol inhibits hypoxiainduced angiogenesis," BMB Reports, vol. 49, no. 9, pp. 508-513, 2016.

[29] S.-W. Choi, Y.-J. Son, J.-M. Yun, and S. H. Kim, "Fisetin inhibits osteoclast differentiation via downregulation of p38 and c-FosNFATc1 signaling pathways," Evidence-Based Complementary and Alternative Medicine, vol. 2012, Article ID 810563, 9 pages, 2012.

[30] C. Dannemann, K. W. Grätz, M. O. Riener, and R. A. Zwahlen, "Jaw osteonecrosis related to bisphosphonate therapy. A severe secondary disorder," Bone, vol. 40, no. 4, pp. 828-834, 2007.

[31] R. P. H. Meier, T. V. Perneger, R. Stern, R. Rizzoli, and R. E. Peter, "Increasing occurrence of atypical femoral fractures associated with bisphosphonate use," Archives of Internal Medicine, vol. 172, no. 12, pp. 930-936, 2012.

[32] A. Scalbert, C. Manach, C. Morand, and C. Remesy, "Dietary polyphenols and the prevention of diseases," Critical Reviews in Food Science and Nutrition, vol. 45, no. 4, pp. 287-306, 2005.

[33] Y.-H. Lee, J.-H. Kim, S. H. Kim et al., "Barley sprouts extract attenuates alcoholic fatty liver injury in mice by reducing inflammatory response," Nutrients, vol. 8, no. 7, article no. 440, 2016.

[34] A. R. Byun, H. Chun, J. Lee, S. W. Lee, H. S. Lee, and K. W. Shim, "Effects of a dietary supplement with barley sprout extract on blood cholesterol metabolism," Evidence-based Complementary and Alternative Medicine, vol. 2015, Article ID 473056, 7 pages, 2015.

[35] A. Takano, T. Kamiya, H. Tomozawa et al., "Insoluble fiber in young barley leaf suppresses the increment of postprandial blood glucose level by increasing the digesta viscosity," Evidence-Based Complementary and Alternative Medicine, vol. 2013, article 137871, 10 pages, 2013.

[36] J. A. Benedet, H. Umeda, and T. Shibamoto, "Antioxidant activity of flavonoids isolated from young green barley leaves toward biological lipid samples," Journal of Agricultural and Food Chemistry, vol. 55, no. 14, pp. 5499-5504, 2007.

[37] W. J. Boyle, W. S. Simonet, and D. L. Lacey, "Osteoclast differentiation and activation," Nature, vol. 423, no. 6937, pp. 337-342, 2003. 
[38] A. Arai, T. Mizoguchi, S. Harada et al., "Fos plays an essential role in the upregulation of RANK expression in osteoclast precursors within the bone microenvironment," Journal of Cell Science, vol. 125, part 12, pp. 2910-2917, 2012.

[39] A. Fleischmann, F. Hafezi, C. Elliott et al., Fra-1 replaces c-Fosdependent functions in mice, Genes development, vol. 14.

[40] H. Takayanagi, S. Kim, T. Koga et al., "Induction and activation of the transcription factor NFATc1 (NFAT2) integrate RANKL signaling in terminal differentiation of osteoclasts," Developmental Cell, vol. 3, no. 6, pp. 889-901, 2002.

[41] A. Rao, C. Luo, and P. G. Hogan, "Transcription factors of the NFAT family: regulation and function," Annual Review of Immunology, vol. 15, pp. 707-747, 1997.

[42] H. C. Blair, L. J. Robinson, and M. Zaidi, "Osteoclast signalling pathways," Biochemical and Biophysical Research Communications, vol. 328, no. 3, pp. 728-738, 2005.

[43] N. Kobayashi, Y. Kadono, A. Naito et al., "Segregation of TRAF6-mediated signaling pathways clarifies its role in osteoclastogenesis," EMBO Journal, vol. 20, no. 6, pp. 1271-1280, 2001.

[44] B. R. Wong, D. Besser, N. Kim et al., "TRANCE, a TNF family member, activates Akt/PKB through a signaling complex involving TRAF6 and c-Src," Molecular Cell, vol. 4, no. 6, pp. 1041-1049, 1999.

[45] B. R. Wong, R. Josien, S. Y. Lee, M. Vologodskaia, R. M. Steinman, and Y. Choi, "The TRAF family of signal transducers mediates NF- $\kappa \mathrm{B}$ activation by the TRANCE receptor," The Journal of Biological Chemistry, vol. 273, no. 43, pp. 2835528359, 1998.

[46] M. D. Jacobs and S. C. Harrison, "Structure of an $\mathrm{I} \kappa \mathrm{B} \alpha / \mathrm{NF}-\kappa \mathrm{B}$ complex," Cell, vol. 95, no. 6, pp. 749-758, 1998.

[47] M. L. Chaisson, D. G. Branstetter, J. M. Derry et al., "Osteoclast differentiation is impaired in the absence of inhibitor of $\kappa \mathrm{B}$ kinase $\alpha$," Journal of Biological Chemistry, vol. 279, no. 52, pp. 54841-54848, 2004.

[48] V. Iotsova, J. Caamaño, J. Loy, Y. Yang, A. Lewin, and R. Bravo, "Osteopetrosis in mice lacking NF- $\kappa$ B1 and NF- $\kappa$ B2," Nature Medicine, vol. 3, no. 11, pp. 1285-1289, 1997.

[49] M. Asagiri and H. Takayanagi, "The molecular understanding of osteoclast differentiation," Bone, vol. 40, no. 2, pp. 251-264, 2007.

[50] T. Suda, N. Takahashi, N. Udagawa, E. Jimi, M. T. Gillespie, and T. J. Martin, "Modulation of osteoclast differentiation and function by the new members of the tumor necrosis factor receptor and ligand families," Endocrine Reviews, vol. 20, no. 3, pp. 345-357, 1999.

[51] R. Islam, H.-S. Bae, W.-J. Yoon et al., "Pin1 regulates osteoclast fusion through suppression of the master regulator of cell fusion DC-STAMP," Journal of Cellular Physiology, vol. 229, no. 12, pp. 2166-2174, 2014.

[52] C. Zhang, C. Dou, J. Xu, and S. Dong, "DC-STAMP, the key fusion-mediating molecule in osteoclastogenesis," Journal of Cellular Physiology, vol. 229, no. 10, pp. 1330-1335, 2014.

[53] N. Courtial, J. J. Smink, O. N. Kuvardina, A. Leutz, J. R. Göthert, and J. Lausen, "Tall regulates osteoclast differentiation through suppression of the master regulator of cell fusion DC-STAMP," FASEB Journal, vol. 26, no. 2, pp. 523-532, 2012.

[54] M. Yagi, T. Miyamoto, Y. Sawatani et al., "DC-STAMP is essential for cell-cell fusion in osteoclasts and foreign body giant cells," Journal of Experimental Medicine, vol. 202, no. 3, pp. 345351, 2005.
[55] T. Miyamoto, "The dendritic cell-specific transmembrane protein DC-STAMP is essential for osteoclast fusion and osteoclast bone-resorbing activity," Modern Rheumatology, vol. 16, no. 6, pp. 341-342, 2006.

[56] S. L. Teitelbaum, "Bone resorption by osteoclasts," Science, vol. 289, no. 5484, pp. 1504-1508, 2000.

[57] A. Erlebacher, E. H. Filvaroff, S. E. Gitelman, and R. Derynck, "Toward a molecular understanding of skeletal development," Cell, vol. 80, no. 3, pp. 371-378, 1995.

[58] V. Everts, J. Delaissé, W. Korper, A. Niehof, G. Vaes, and W. Beertsen, "Degradation of collagen in the bone-resorbing compartment underlying the osteoclast involves both cysteine-proteinases and matrix metalloproteinases," Journal of Cellular Physiology, vol. 150, no. 2, pp. 221-231, 1992.

[59] T. Ishikawa, M. Kamiyama, N. Tani-Ishii et al., "Inhibition of osteoclast differentiation and bone resorption by cathepsin $\mathrm{k}$ antisense oligonucleotides," Molecular Carcinogenesis, vol. 32, no. 2, pp. 84-91, 2001.

[60] B. D. Gelb, G.-P. Shi, H. A. Chapman, and R. J. Desnick, "Pycnodysostosis, a lysosomal disease caused by cathepsin K deficiency," Science, vol. 273, no. 5279, pp. 1236-1238, 1996.

[61] D. Brömme, K. Okamoto, B. B. Wang, and S. Biroc, "Human cathepsin $\mathrm{O}_{2}$, a matrix protein-degrading cysteine protease expressed in osteoclasts: functional expression of human cathepsin $\mathrm{O}_{2}$ in Spodoptera frugiperda and characterization of the enzyme," Journal of Biological Chemistry, vol. 271, no. 4, pp. 2126-2132, 1996.

[62] P. Leung, M. Pickarski, Y. Zhuo, P. J. Masarachia, and L. T. Duong, "The effects of the cathepsin $\mathrm{K}$ inhibitor odanacatib on osteoclastic bone resorption and vesicular trafficking," Bone, vol. 49, no. 4, pp. 623-635, 2011.

[63] V. Everts, D. C. Aronson, and W. Beertsen, "Phagocytosis of bone collagen by osteoclasts in two cases of pycnodysostosis," Calcified Tissue International, vol. 37, no. 1, pp. 25-31, 1985.

[64] M. Matsumoto, M. Kogawa, S. Wada et al., "Essential role of p38 mitogen-activated protein kinase in cathepsin $\mathrm{K}$ gene expression during osteoclastogenesis through association of NFATc1 and PU.1," The Journal of Biological Chemistry, vol. 279, no. 44, pp. 45969-45979, 2004. 


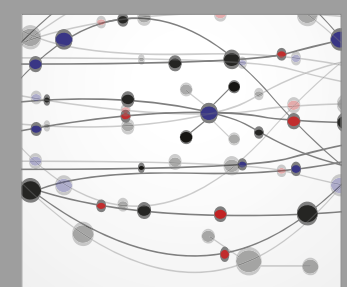

The Scientific World Journal
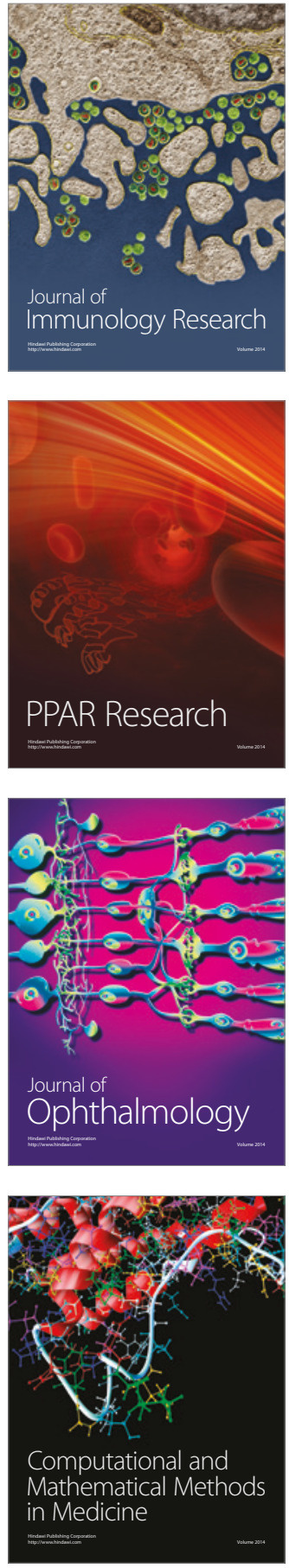

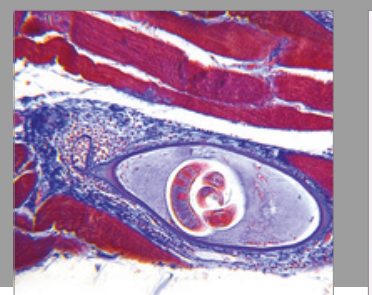

Gastroenterology Research and Practice
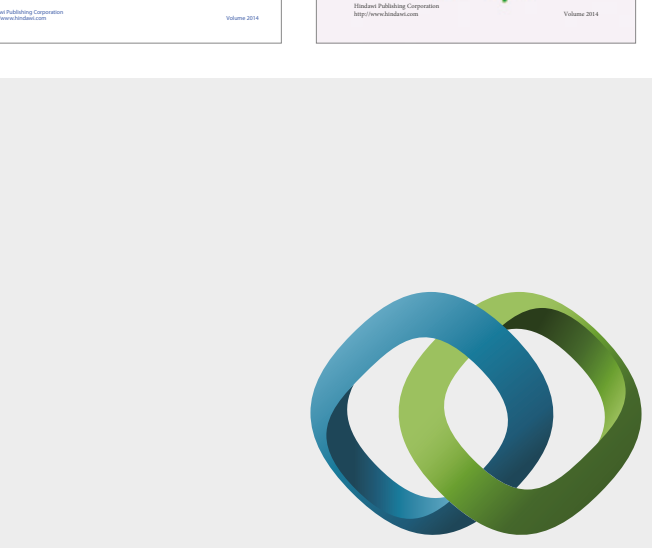

\section{Hindawi}

Submit your manuscripts at

https://www.hindawi.com
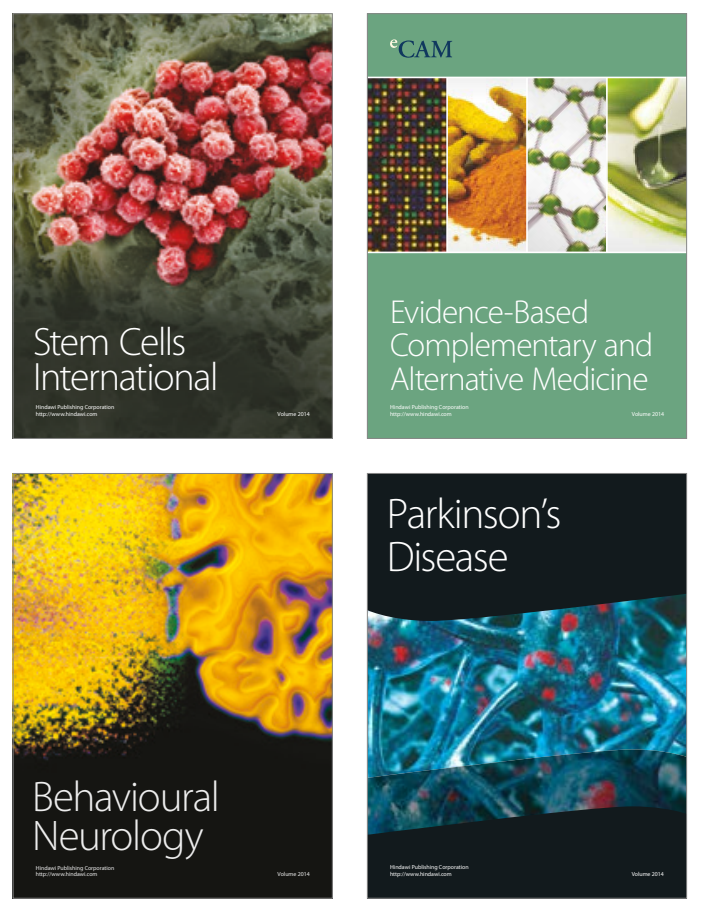
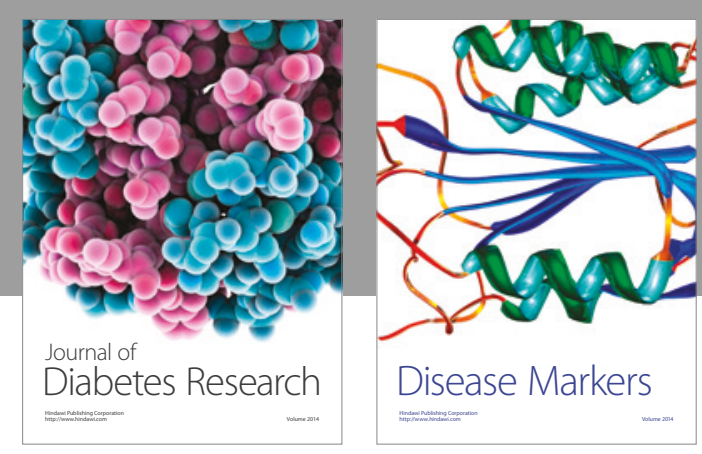

Disease Markers
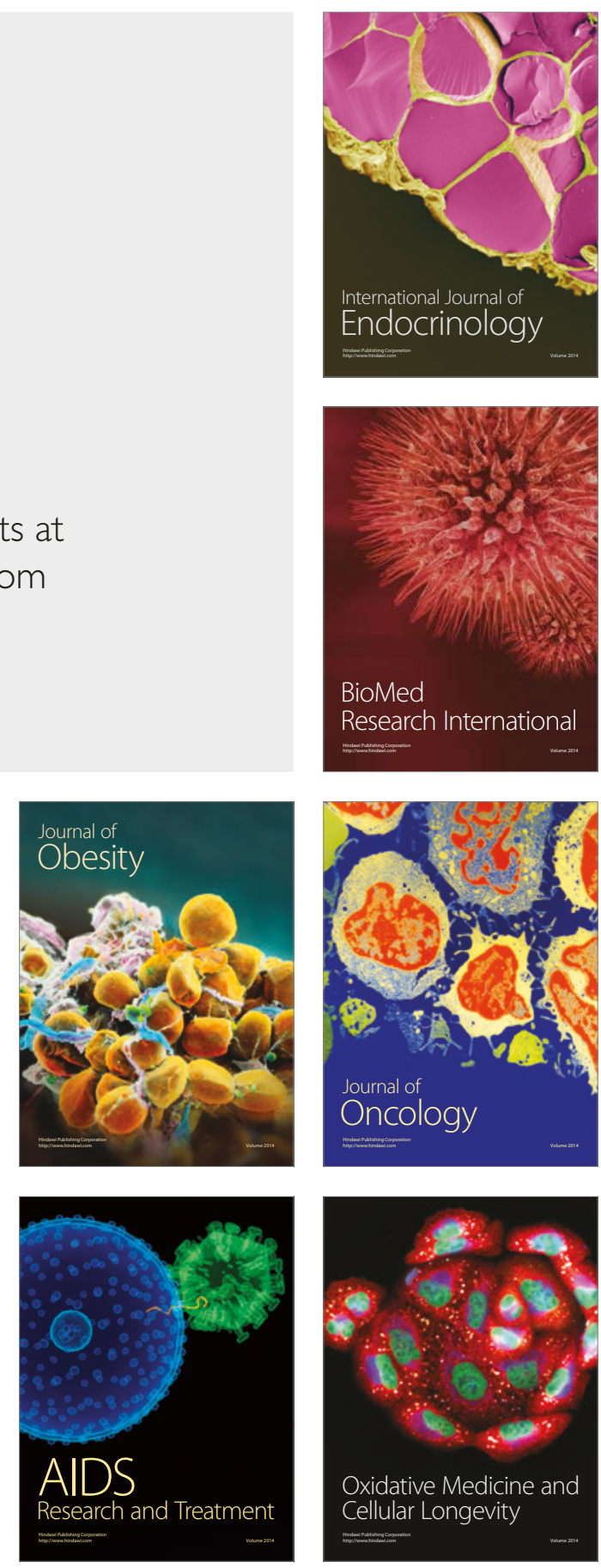